Article

\title{
Disposable Electrochemical Sensor for Food Colorants Detection by Reduced Graphene Oxide and Methionine Film Modified Screen Printed Carbon Electrode
}

\author{
Chutimon Akkapinyo ${ }^{1}$, Kittitat Subannajui ${ }^{2}$, Yingyot Poo-arporn ${ }^{3}$ and Rungtiva P. Poo-arporn ${ }^{1, * \mathbb{D}}$ \\ 1 Biological Engineering Program, Faculty of Engineering, King Mongkut's University of Technology Thonburi, \\ Bangkok 10140, Thailand; chutimon.akk@gmail.com \\ 2 School of Materials Science and Innovation, Faculty of Science, Mahidol University, Bangkok 10400, Thailand; \\ kittitat.sub@mahidol.ac.th \\ 3 Synchrotron Light Research Institute, 111 University Avenue, Nakhon Ratchasima 30000, Thailand; \\ yingyot@slri.or.th \\ * Correspondence: rungtiva.pal@kmutt.ac.th; Tel.: +66-24709393
}

check for

updates

Citation: Akkapinyo, C.; Subannajui, K.; Poo-arporn, Y.; Poo-arporn, R.P. Disposable Electrochemical Sensor for Food Colorants Detection by Reduced Graphene Oxide and Methionine Film Modified Screen Printed Carbon Electrode. Molecules 2021, 26, 2312. https://doi.org/10.3390/ molecules26082312

Academic Editor: Antonella Curulli

Received: 15 March 2021

Accepted: 14 April 2021

Published: 16 April 2021

Publisher's Note: MDPI stays neutral with regard to jurisdictional claims in published maps and institutional affiliations.

Copyright: (c) 2021 by the authors. Licensee MDPI, Basel, Switzerland. This article is an open access article distributed under the terms and conditions of the Creative Commons Attribution (CC BY) license (https:/ / creativecommons.org/licenses/by/ $4.0 /)$.

\begin{abstract}
A facile synthesis of reduced graphene oxide (rGO) and methionine film modified screen printed carbon electrode (rGO-methionine/SPCE) was proposed as a disposable sensor for determination of food colorants including amaranth, tartrazine, sunset yellow, and carminic acid. The fabrication process can be achieved in only 2 steps including drop-casting of rGO and electropolymerization of poly(L-methionine) film on SPCE. Surface morphology of modified electrode was studied by scanning electron microscopy (SEM). This work showed a successfully developed novel disposable sensor for detection of all 4 dyes as food colorants. The electrochemical behavior of all 4 food colorants were investigated on modified electrodes. The rGO-methionine/SPCE significantly enhanced catalytic activity of all 4 dyes. The $\mathrm{pH}$ value and accumulation time were optimized to obtain optimal condition of each colorant. Differential pulse voltammetry (DPV) was used for determination, and two linear detection ranges were observed for each dye. Linear detection ranges were found from 1 to 10 and 10 to $100 \mu \mathrm{M}$ for amaranth, 1 to 10 and 10 to $85 \mu \mathrm{M}$ for tartrazine, 1 to 10 and 10 to $50 \mu \mathrm{M}$ for sunset yellow, and 1 to 20 and 20 to $60 \mu \mathrm{M}$ for carminic acid. The limit of detection (LOD) was calculated at 57, 41, 48, and $36 \mathrm{nM}$ for amaranth, tartrazine, sunset yellow, and carminic acid, respectively. In addition, the modified sensor also demonstrated high tolerance to interference substances, good repeatability, and high performance for real sample analysis.
\end{abstract}

Keywords: azo dyes; amaranth; carminic acid; methionine; reduced graphene oxide; sunset yellow; tartrazine; sensor

\section{Introduction}

Recently, food colorants have demonstrated an outstanding role in improving food appearance and making them look more attractive. There are many of synthetic and natural dyes that are used in the food industry. Nevertheless, excessive consumption of some colorants can lead to health risks. Therefore, the food law is required to control the amount of hazardous dyes in food.

Azo dyes are the most popular synthetic dye in the food industry. About $70 \%$ of syn-thetic food colorant belongs to azo dyes. In general, this dye is utilized for coloring of con-fectioneries, soft drinks, and alcoholic beverages. However, health effects were revealed for excessive consumption. The azo dye molecule can be cleaved into aromatic amines, which are suspected to be carcinogens and mutagens [1]. Moreover, superexcitation and hyper-activity in children were revealed for overconsumption [2]. To manage health risks, Euro-pean Food Safety Authority (EFSA) defined the acceptable daily intake (ADI) for each azo dye. For example, ADI was set at $0.15,4.0$, and $7.5 \mathrm{mg} / \mathrm{kg}$ body weight for amaranth (AM), sunset yellow (SY), and tartrazine (TZ), respectively [3-5]. The chemical 
structure of ama-ranth, tartrazine, and sunset yellow are illustrated in Scheme 1. Given that the molecule contains azo group $(-\mathrm{N}=\mathrm{N}-)$, it is possible to be reduced by electrochemical reduction. Moreover, there is a hydroxyl group on their chemical structure, thus they can be oxidized as well [6].<smiles>O=S(=O)([O-])c1ccc2c(/N=N/c3ccc(S(=O)(=O)[O-])c4ccccc34)c(O)c(S(=O)(=O)[O-])cc2c1</smiles>

Amaranth<smiles>O=S(=O)([O-])c1ccc(NNc2c(O)ccc3cc(S(=O)(=O)[O-])ccc23)cc1</smiles>

Sunset yellow<smiles>O=C(O)C1NN(c2ccc(S(=O)(=O)[O-])cc2)C(O)C1/N=N/c1ccc(S(=O)(=O)[O-])cc1</smiles>

Tartrazine<smiles>Cc1c(C(=O)O)c(O)cc2c1C(=O)c1c(O)c([C@H]3O[C@H](CO)[C@@H](O)[C@H](O)[C@H]3O)c(O)c(O)c1C2=O</smiles><smiles>CSCCC(N)C(=O)O</smiles>

Methionine

Scheme 1. Chemical structure of amaranth, tartrazine, sunset yellow, carminic acid, and methionine.

As the consumer requires foods to be as natural as possible, natural dyes are an al-ternative way of coloring food. Carminic acid (CA) is a red shade natural dye obtained from dried bodies of insects, Dactylopius coccus. The chemical structure of carminic acid is illustrated in Scheme 1. Its chemical structure consists of a glucose and an anthraquinone [7]. In comparison with azo dyes, carminic acid does not exhibit carcinogenic and toxic properties [8]. Given that carminic acid is produced from insects, there are insect proteins left over from the manufacturing process. These proteins can trigger acute hypersensitivity reactions and cause severe anaphylactic reactions [8]. Moreover, due to the low molecular size of carminic acid, it can act as a hapten and trigger immune response when it combines with large carrier molecules such as proteins [9]. Consequently, EFSA defined ADI of carminic acid at $2.5 \mathrm{mg} / \mathrm{kg}$ body weight and introduced the appropriate purifica-tion to reduce allergens as much as possible [8]. Therefore, an effective and reliable method is required for detecting those food colorants.

Due to high sensitivity, high specificity, low cost, short time analysis, and simplicity, electrochemical methods were widely proposed for food dyes determination instead of conventional methods, i.e., spectrophotometry [10,11], chromatography [12], and capillary 
electrophoresis [13]. According to azo and hydroxyl group of azo dyes, direct voltammetric determination is divided into 2 categories including cathodic reduction and anodic oxidation. However, azo dyes determination by azo reduction attracts less attention than hydroxyl oxidation due to the problem of removal of dissolved oxygen [6]. The reduction of dissolved oxygen can alter the cathodic current response of azo dyes. To improve sensitiv-ity and specificity, nanomaterials or chemicals were modified on several types of electrode.

Graphene is a single layer of carbon atoms arranged in a hexagonal lattice. This structure confers fascinating properties to graphene including large surface area and high electrical conductivity [14]. Therefore, graphene and its derivatives as a hybrid material have been widely used in electrochemical sensor field.

Given that amino acids contain amine $\left(-\mathrm{NH}_{2}\right)$ and carboxyl $(-\mathrm{COOH})$ functional groups, they are able to form conductive polymer by electropolymerization. Beside electrocatalytic activity improvement, poly(amino acid) film also provides more active sites for target analytes resulting in sensitivity and selectivity enhancement of the sensor [15]. Therefore, poly(amino acid) has received great attention to modify on electrode surface for sensitivity improvement. Various substances have been determined by amino acid based electrochemical sensor, for example, butylated hydrox-yanisole (BHA) [16], simultaneous detection of uric acid, xanthine and hypoxanthine [17], and epinephrine [18]. Moreover, there is a cooperation between poly(amino acid) film and other nanomaterials to increase electrode's sensitivity, for example, methionine/gold na-noparticles modified glassy carbon electrode (GCE) for hydroquinone determination. With high surface area and strong adsorptive ability of methionine/gold nanoparticles film, the accumulation of hydroquinone on the electrode was improved [19]. Poly(L-arginine)/graphene composite film modified GCE was proposed for simultaneous determination of uric acid, xanthine, and hypoxanthine. With the catalytic property of poly(L-arginine) and excellent electric conductivity of graphene, the electrochemical signal was amplified [20]. In addition, poly(amino acid) film was used for azo dyes determination as well [21-26]. On the other hand, only a few reports based on poly(amino acid) film was proposed for electrochemical determination of carmine [21]. However, previous poly (amino acid) film based electrochemical sensor for azo dyes determination is still em-ployed on traditional electrodes, i.e., GCE, carbon paste electrode or even pencil graphite electrode. Although these types of electrodes exhibit high sensitivity, they still lack the ca-pability for on-site detection. Due to the limitation of high cost, they need to be cleaned for reuse. This stint makes traditional electrodes inappropriate for mass production. Screen printed carbon electrode (SPCE) was proposed to break these limitations. SPCE demon-strates various advantages such as low fabrication cost, variable configuration, and being able to be produced for large scale. Thus, SPCE is appropriate to use for on-site detection. However, to the best of our knowledge, there is no report of electrochemical sensors based on reduced graphene oxide (rGO) and methionine film modified SPCE for azo dyes and carminic acid determination. Therefore, this is the first developed novel disposable sensor for detection of 4 dyes; amaranth, tartrazine, sunset yellow, and carminic acid.

This work aims to develop a disposable sensor for food colorants detection. The chemical structure of methionine presents in Scheme 1. The synergistic effect of rGO and methio-nine film are proposed for sensitivity improvement of SPCE. Poly(L-methionine) film and rGO were modified on SPCE for determination of carminic acid and 3 azo dyes (amaranth, tartrazine, and sunset yellow). With synergistic effect, the modified electrode demonstrated good catalytic activity to target analytes. Moreover, the modified SPCE demonstrated good performance for real sample analysis.

\section{Results and Discussion}

\subsection{Morphology of Modified Electrode}

The morphology of bare SPCE, rGO/SPCE, and rGO-Methionine/SPCE were characterized by SEM as demonstrated in Figure 1a-c. The bare SPCE presented rough surface 
while smooth surface was observed on rGO/SPCE. The smooth surface is the layer of rGO that covered the SPCE. Thereafter, polymeric layer was observed on the layer of rGO after electrochemical polymerization of methionine film on rGO/SPCE. SEM result demonstrat-ed successful deposition of $\mathrm{rGO}$ and electropolymerization of methionine on SPCE. The insets of Figure 1a-c represent the image of bare SPCE, rGO/SPCE, and rGO-methionine/SPCE taking by light microscope. Bare SPCE demonstrated rough surface which was different to rGO/SPCE and rGO-methionine/SPCE. With the modification of rGO, the smoother surface was observed on rGO/SPCE and rGO-methionine/SPCE. More-over, with the methionine film covering, the fine surface demonstrated on rGOmethionine/SPCE. Thus, the results from microscopic image can ensure the success-ful modification of rGO and methionine film on SPCE.

(a)

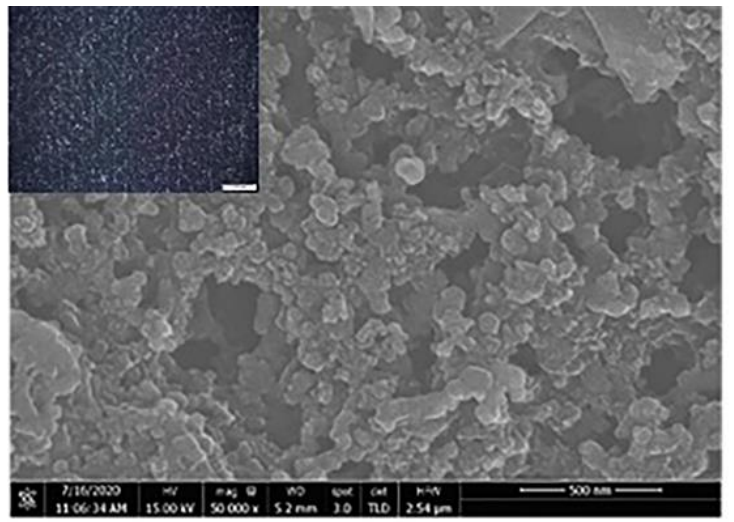

(b)

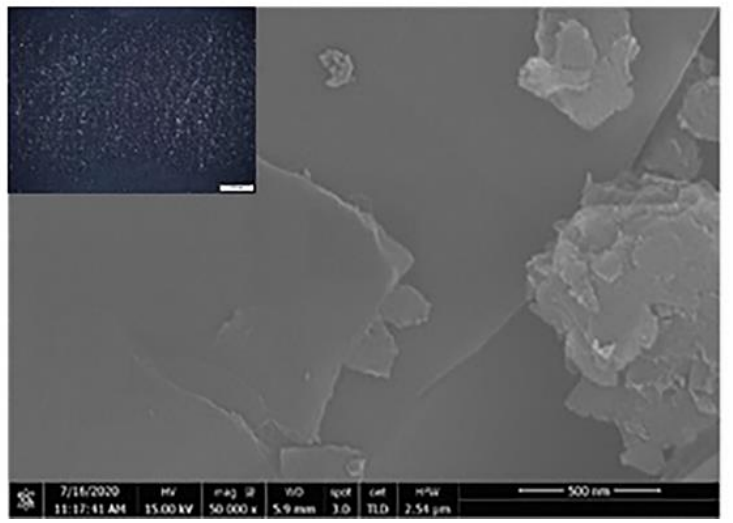

(c)

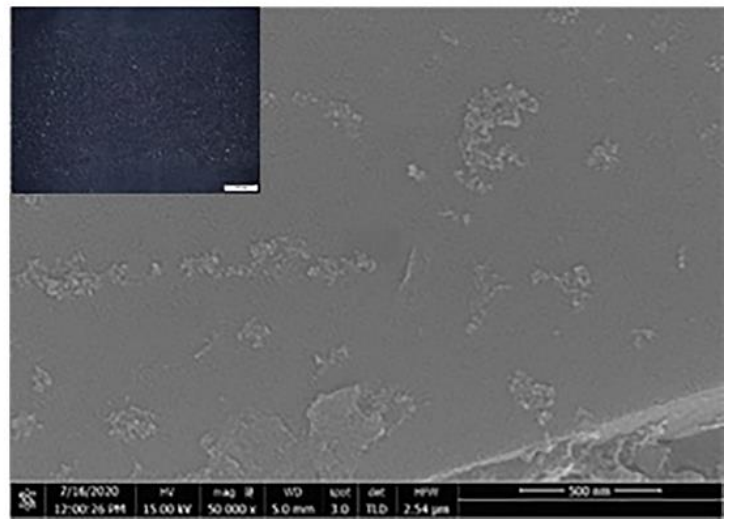

Figure 1. SEM images of bare SPCE (a), rGO/SPCE (b), and rGO-methionine/SPCE (c). The insets of (a-c) are the stereomicroscopic at $10 \times$ magnificent of bare SPCE rGO/SPCE and rGO-methionine/SPCE, respectively.

\subsection{Electrochemical Characterization of Electrode Modification}

To study the effect of rGO and methionine on SPCE and characterize the modification process, cyclic voltammetry (CV) and electrochemical impedance spectroscopy (EIS) were used to investigate each step of SPCE modification. A $5 \mathrm{mM}$ of ferricyanide/ferrocianyde redox couple $\left(\mathrm{Fe}(\mathrm{CN})_{6}{ }^{3-/ 4-}\right)$ containing $0.1 \mathrm{M} \mathrm{KCl}$ was used as electrolyte. The cyclic voltammograms of $\mathrm{rGO} / \mathrm{SPCE}$, methionine/SPCE, and rGO-methionine/SPCE were compared with bare SPCE at scan rate of $50 \mathrm{mV} / \mathrm{s}$ as illustrated in Figure 2a. The current response was the signal of the redox probe. The obtained current response increased from bare SPCE, methionine/SPCE, rGO/SPCE, and rGO-methionine/SPCE, respectively. Given that the effect of high surface area of rGO can accelerate electron transfer [14], the current response was significantly increased on $\mathrm{rGO} / \mathrm{SPCE}$. The obtained current response of rGO/SPCE increased almost 5 times to bare SPCE. However, since methionine film is a barely conductive material, the catalytic current increased slightly after modification on bare SPCE and rGO/SPCE. Moreover, the result demonstrated the same tendency 
with EIS as depicted in Figure 2b. EIS was performed at amplitude of $10 \mathrm{mV}$. The charge transfer re-sistance (Rct) of bare SPCE and methionine/SPCE were interpreted by Randle's equivalent circuit. Bare SPCE exhibited the largest Rct $(38.49 \pm 1.74 \mathrm{k} \Omega)$ as a result of the poor conduc-tivity of SPCE. For methionine/SPCE, the semicircle can still be observed, but it was smaller than bare SPCE. The Rct was found to be $29.79 \pm 2.22 \mathrm{k} \Omega$. However, the semicircle was not revealed on both rGO and rGO-methionine/SPCE. This can be attributed to $\mathrm{rGO}$, which can improve the conductivity of SPCE. Moreover, we can prove that rGO and methionine film was successfully modified on SPCE by the changed current response and Rct of each step of modification.
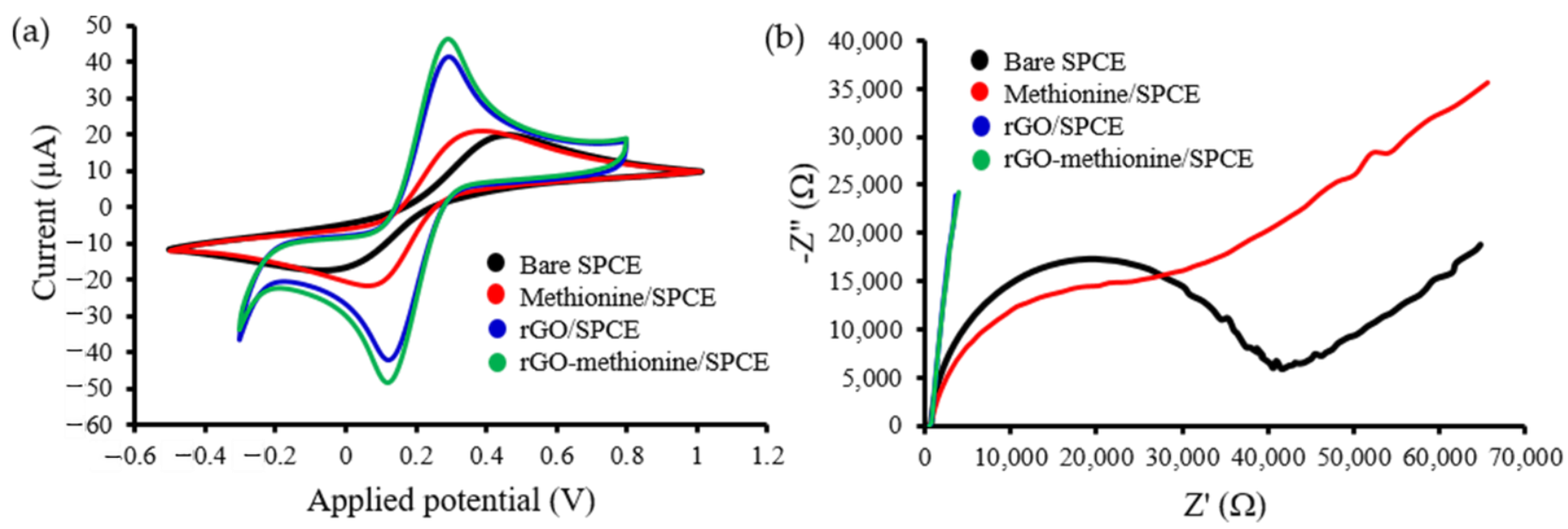

Figure 2. Electrochemical characterization of electrode modification by CV at scan rate $50 \mathrm{mV} / \mathrm{s} \mathrm{(a)} \mathrm{and} \mathrm{EIS} \mathrm{(b).}$

\subsection{Electrochemical Behavior of Amaranth, Tartrazine, Sunset Yellow and Carminic Acid on Modified Electrode}

The electrochemical behavior of each dye was tested separately on rGO-methionine/ SPCE in comparison with bare SPCE and rGO/SPCE to investigate performance of modified sensor. CV was used to study the electrochemical behavior of all 4 dyes. Cyclic voltammograms of 0 and $10 \mu \mathrm{M}$ of amaranth, 0 and $50 \mu \mathrm{M}$ of tartrazine, 0 and $50 \mu \mathrm{M}$ of sunset yellow, and 0 and $50 \mu \mathrm{M}$ of carminic acid were recorded as demonstrated in Figure $3 a-d$, respectively. The results demonstrated that catalytic current response was observed only when the detected dyes presented in the samples. Thus, the current response was the signal of the detected dyes. The oxidative current responses of each dye on bare SPCE, rGO/SPCE, and rGO-methionine/SPCE are presented in Table 1. For amaranth, acetate buffer $\mathrm{pH} 4.0$ was used as the supporting electrolyte. The anodic peak of amaranth was observed at about $0.8 \mathrm{~V}$, and no cathodic peak was observed on all of 3 different modified electrodes, as shown in Figure 3a. Only anodic peak was also observed for tartrazine. The oxidation peak appeared at a potential of about $1.05 \mathrm{~V}$ in citrate-phosphate buffer $\mathrm{pH}$ 3.0 (Figure $3 \mathrm{~b}$ ). For sunset yellow, voltammograms were recorded by using phosphate buffer $\mathrm{pH}$ 7.0, while carminic acid used citrate phosphate buffer $\mathrm{pH} 3.0$ as electrolyte. Both of sunset yellow and carminic acid demonstrated a pair of redox peak as illustrated in Figure $3 c, d$, respectively.

All 4 dyes represented the consistent result. Bare SPCE demonstrated small electrochemical current response indicating weak catalytic activity of dyes on bare electrode, while the rGO/SPCE significantly enhanced the electrochemical response of all 4 dyes. With the high conductive property, the rGO film can help to facilitate electron transfer rate on electrode. This phenomenon affects the improvement of sensitivity [14]. Moreover, the layer of poly(L-methionine) film has a good catalytic effect due to its active groups, such as amino group and carboxyl group $[17,25]$. In addition, the result showed that methionine film decreased the background current of rGO. The well-defined peak was observed on rGO-methionine/SPCE. With the synergistic effect between rGO and poly(L-methionine) 
film, the catalytic activity of amaranth, tartrazine, sunset yellow, and carminic acid were significantly enhanced on rGO-methionine/SPCE.

Table 1. Electrochemical response of amaranth, tartrazine, sunset yellow, and carminic acid on bare SPCE, rGO/SPCE, and rGO-methionine/SPCE.

\begin{tabular}{|c|c|c|c|}
\hline Dye & Electrode & Dye Concentration $(\mu \mathrm{M})$ & Oxidative Current $(\mu \mathrm{A})$ \\
\hline \multirow{3}{*}{ Amaranth } & Bare SPCE & \multirow{3}{*}{10} & $0.09 \pm 0.01$ \\
\hline & rGO/SPCE & & $0.94 \pm 0.08$ \\
\hline & rGO-methionine/SPCE & & $1.05 \pm 0.12$ \\
\hline \multirow{3}{*}{ Tartrazine } & Bare SPCE & \multirow{3}{*}{50} & $0.41 \pm 0.01$ \\
\hline & $\mathrm{rGO} / \mathrm{SPCE}$ & & $1.45 \pm 0.20$ \\
\hline & rGO-methionine/SPCE & & $3.28 \pm 0.51$ \\
\hline \multirow{3}{*}{ Sunset yellow } & Bare SPCE & \multirow{3}{*}{50} & $0.45 \pm 0.04$ \\
\hline & $\mathrm{rGO} / \mathrm{SPCE}$ & & $1.52 \pm 0.22$ \\
\hline & rGO-methionine/SPCE & & $1.77 \pm 0.37$ \\
\hline \multirow{3}{*}{ Carminic acid } & Bare SPCE & \multirow{3}{*}{50} & $0.35 \pm 0.01$ \\
\hline & $\mathrm{rGO} / \mathrm{SPCE}$ & & $1.49 \pm 0.23$ \\
\hline & rGO-methionine/SPCE & & $1.76 \pm 0.33$ \\
\hline
\end{tabular}

(a)
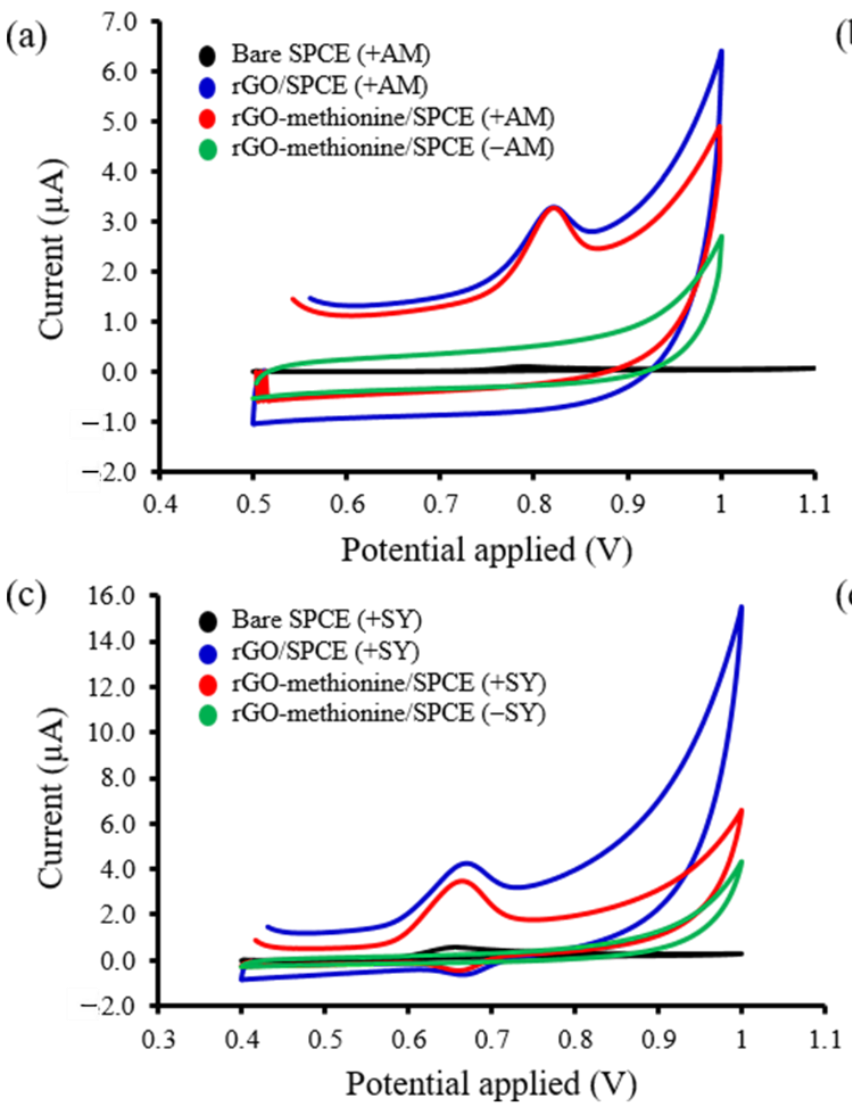
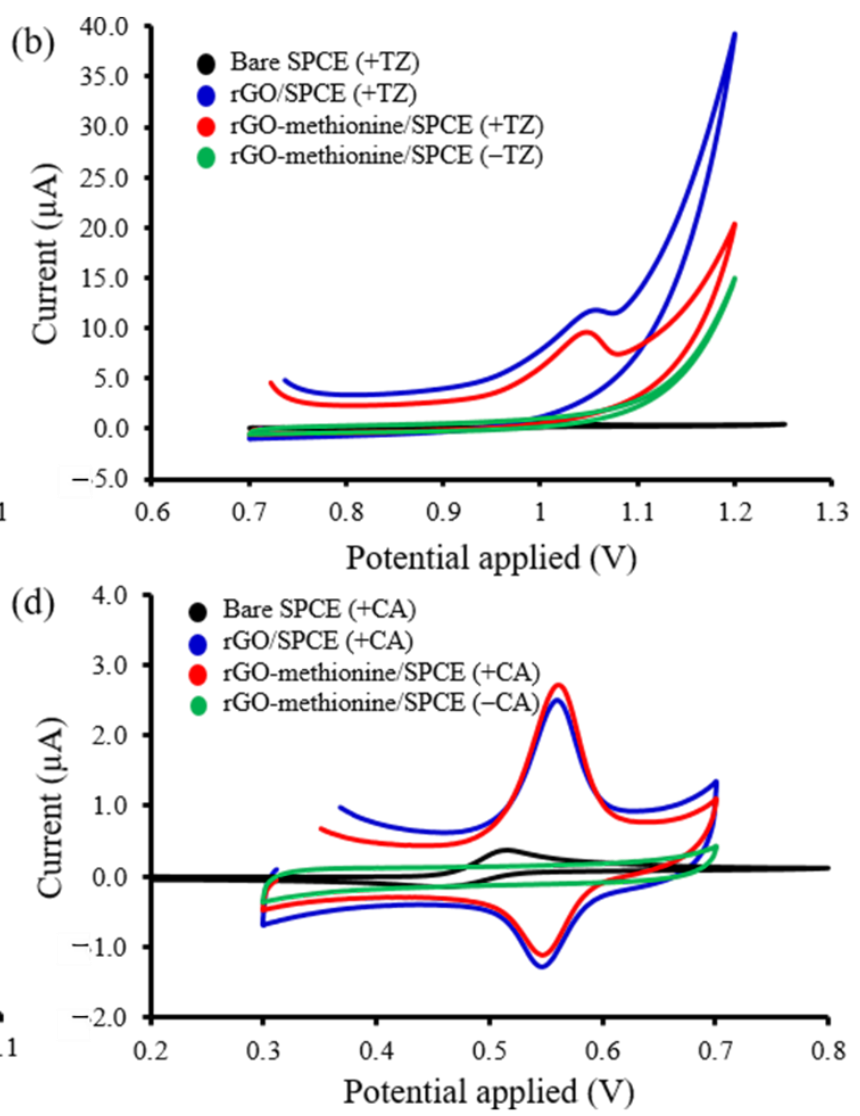

Figure 3. $\mathrm{CV}$ curves of 0 and $10 \mu \mathrm{M}$ amaranth (a), 0 and $50 \mu \mathrm{M}$ Tartrazine (b), 0 and $50 \mu \mathrm{M}$ sunset yellow (c), 0 and $50 \mu \mathrm{M}$ of carminic acid (d) on bare SPCE (black), rGO/SPCE (blue), and rGO-methionine modified SPCE (red) at scan rate $20 \mathrm{mv} / \mathrm{s}$.

\subsection{Effect of $\mathrm{pH}$ of Electrolyte}

The appropriate electrolyte and its $\mathrm{pH}$ is the most important factor required to obtain the best catalytic current response, therefore various types of electrolytes at different $\mathrm{pH}$ values, including citrate-phosphate buffer at $\mathrm{pH} 2.5$ and 3.0, acetate buffer at $\mathrm{pH} 4.0$ and 5.0, and phosphate buffer at $\mathrm{pH} 6.0,7.0$, and 8.0, were investigated. The effect of $\mathrm{pH}$ on the 
catalytic activity of $50 \mu \mathrm{M}$ amaranth, tartrazine, sunset yellow, and carminic acid was studied on rGO-methionine/SPCE by DPV. The results are illustrated in Figure $4 \mathrm{a}-\mathrm{h}$. Catalytic activities of amaranth, tartrazine, sunset yellow, and carminic acid were $\mathrm{pH}$ dependent. The anodic peak potential of all 4 dyes shifted to a negative direction with further increase in $\mathrm{pH}$. This evidence can be attributed to the participation of protons in electrode reaction. In addition, the relationship between peak potential (Ep) and $\mathrm{pH}$ value was investigated. The linear regressions were demonstrated as $\mathrm{E}(\mathrm{AM})=0.9203-0.0322 \mathrm{pH}, \mathrm{R}^{2}=0.9987$ for amaranth, $\mathrm{E}(\mathrm{TZ})=1.1122-0.0328 \mathrm{pH}, \mathrm{R}^{2}=0.9945$ for tartrazine, $\mathrm{E}(\mathrm{SY})=0.8611-0.0315 \mathrm{pH}$, $\mathrm{R}^{2}=0.9993$ for sunset yellow, and $\mathrm{E}(\mathrm{CA})=0.7760-0.0777 \mathrm{pH}, \mathrm{R}^{2}=0.9981$ for carminic acid. The slope values at $0.0322,0.0328$, and 0.0315 of amaranth, tartrazine, and sunset yellow were close to half of theoretical value $(0.059 \mathrm{~V} / \mathrm{pH})$. Therefore, the ratio between proton and electron in the reaction was equal to 1:2. This ratio is line with previous reports of amaranth [27-29], tartrazine [30,31], and sunset yellow [25,32]. The electrochemical mechanism of amaranth, sunset yellow and tartrazine may be summarized as follow [33]:

$$
\text { Dye }-2 \mathrm{e}^{-} 1 \mathrm{H}^{+} \rightarrow \text { Dye (ox) }
$$

where dye refers to amaranth, sunset yellow, and tartrazine. On the other hand, the slope value between $\mathrm{E}(\mathrm{CA})$ vs. $\mathrm{pH}$ was almost close to the theoretical value, indicating that the number of protons was equal to the number of electrons involved in the reaction. The oxidation of carminic acid was based on hydroquinone [34], and can be summarized as follows:

$$
\text { Carminic acid }-22^{-}-2 \mathrm{H}^{+} \rightarrow \text { Carminic acid (ox) }
$$

To achieve the best condition, the $\mathrm{pH}$ value of the highest oxidative current response was chosen for further experiments. Thus, acetate buffer $\mathrm{pH} 4.0$ was chosen for determination of amaranth, while citrate phosphate buffer $\mathrm{pH} 3.0$ was applied for tartrazine and carminic acid. For sunset yellow, the highest current response was obtained from phosphate buffer pH 7.0, therefore it was chosen for determination of sunset yellow.

\subsection{Effect of Scan Rate}

The influence of scan rate on catalytic activity of amaranth, tartrazine, sunset yellow, and carminic acid were investigated on rGO-methionine/SPCE by CV at scan rate of 10 to $100 \mathrm{mV} / \mathrm{s}$. The obtained optimal $\mathrm{pH}$ value from previous section (Section 2.4) was applied for each dyes. Similar result was observed from all 4 dyes as shown in Figure 5a-d. The catalytic current response increased corresponding to increasing scan rate from 10 to $100 \mathrm{mV} / \mathrm{s}$. The linear equations were obtained as Ipa $=0.0458 \mathrm{v}+0.9022, \mathrm{R} 2=0.9636$ for amaranth, Ipa $=0.1251 \mathrm{v}-0.4153, \mathrm{R}^{2}=0.9637$ for tartrazine, Ipa $=0.0844 \mathrm{v}-0.3744$, $\mathrm{R}^{2}=0.9817$ and Ipc $=-0.0699 \mathrm{v}+1.0699, \mathrm{R}^{2}=0.9702$ for sunset yellow, and Ipa $=0.0864 \mathrm{v}$ $+0.2467, R^{2}=0.9722$ and $I p c=-0.0795 v+0.5845, R^{2}=0.9764$ for carminic acid. The results demonstrated a linear relationship between catalytic current response and scan rate suggesting that electrochemical reactions of amaranth, tartrazine, sunset yellow, and carminic acid on rGO-methionine/SPCE were controlled by adsorption-controlled process.

\subsection{Effect of Accumulation Time}

Given that the catalytic activities of amaranth, tartrazine, sunset yellow, and carminic acid are controlled by adsorption, the effect of accumulation time on rGO-methionine/SPCE was evaluated by DPV. Oxidative current response of $50 \mu \mathrm{M}$ of each dye was evaluated in this experiment. All 4 dyes demonstrated similar results, where catalytic current response increased until it reached saturation time and was stable or dropped slightly after further increase in time, as demonstrated in Figure $6 a-d$. This may be the result of saturation of amaranth, tartrazine, sunset yellow, and carminic acid molecules on the modified electrode [35]. To accomplish the highest response and minimize the detection time, the lowest accumulation time at highest oxidative current was chosen for determination of each dye. 
Consequently, accumulation time at $300 \mathrm{~s}$ was applied for amaranth and sunset yellow, $420 \mathrm{~s}$ for tartrazine, and $240 \mathrm{~s}$ for carminic acid determination.
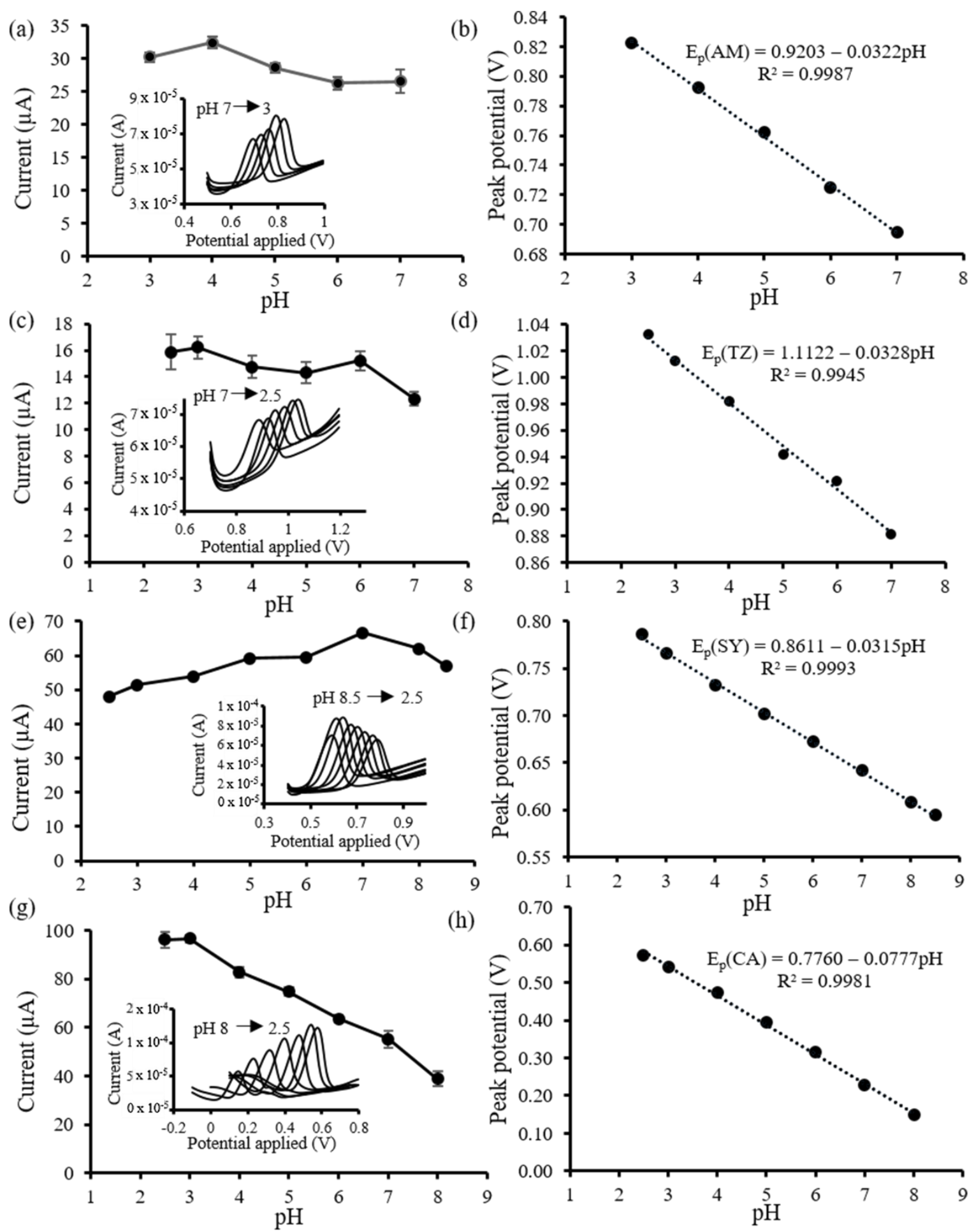

Figure 4. Representation of $\mathrm{pH}$ optimization for amaranth (a), tartrazine (c), sunset yellow (e), and carminic acid (g). The insets illustrate differential pulse voltammograms at different $\mathrm{pH}$ values. The $(\mathbf{b}, \mathbf{d}, \mathbf{f}, \mathbf{h})$ represent linear regression between $\mathrm{pH}$ and anodic peak potential of amaranth, tartrazine, sunset yellow, and carminic acid, respectively. 
(a)

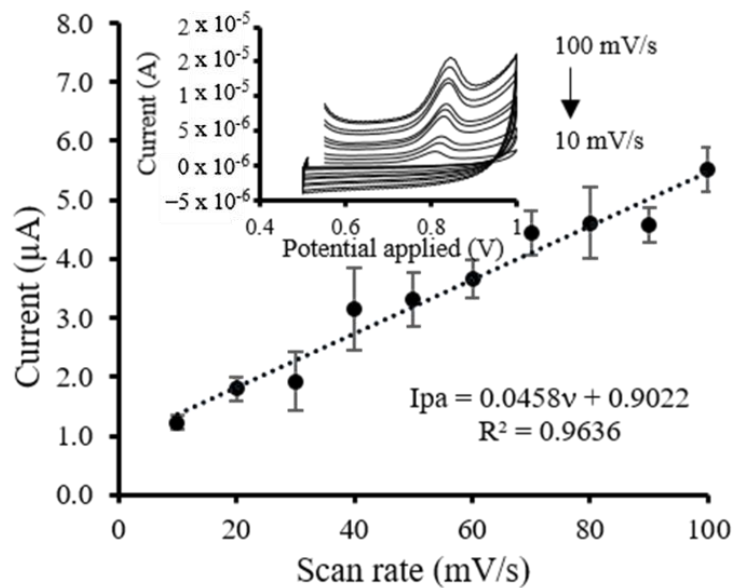

(c)

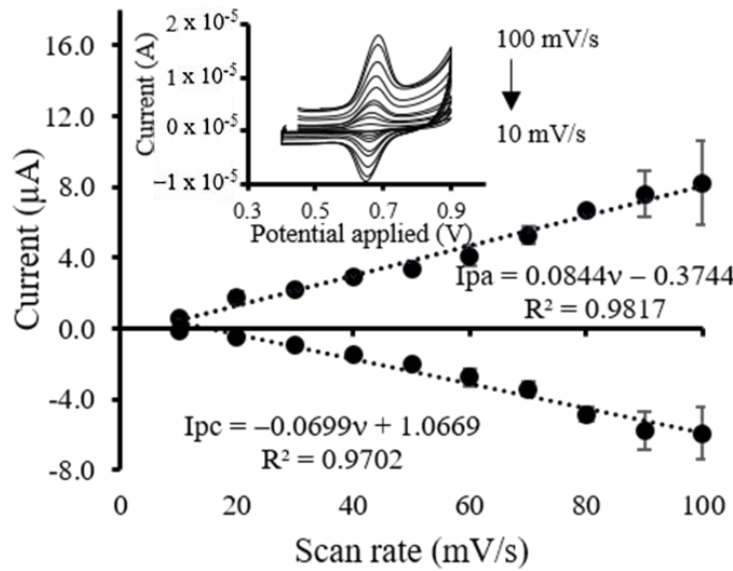

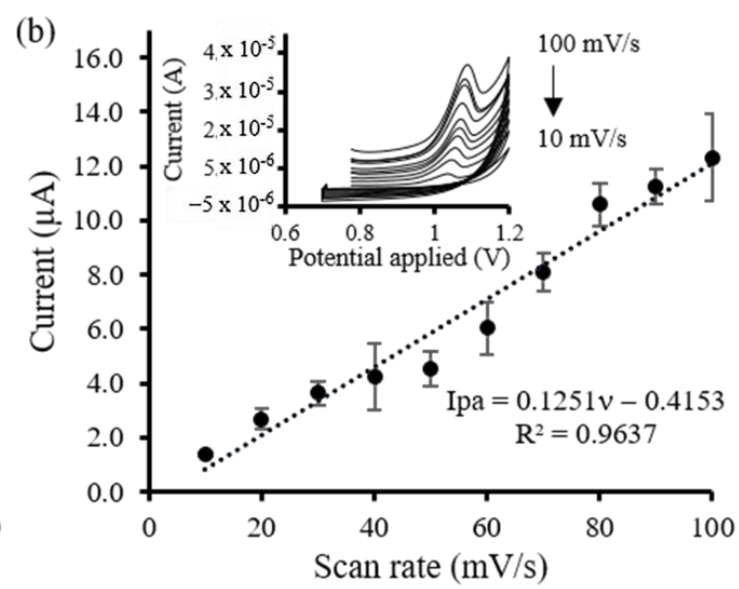

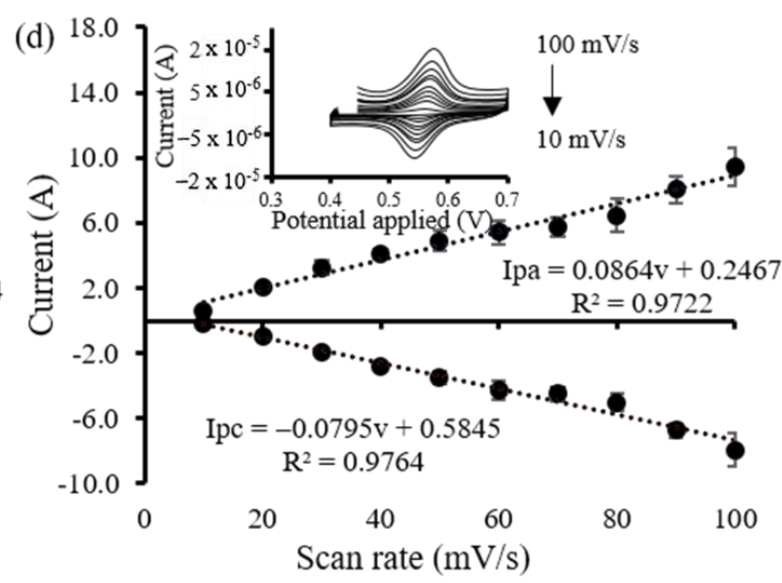

Figure 5. Linear relationship between scan rate and current response of amaranth (a), tartrazine (b), sunset yellow (c), and carminic acid (d). Insets represent obtained cyclic voltammograms at different scan rates.

(a)

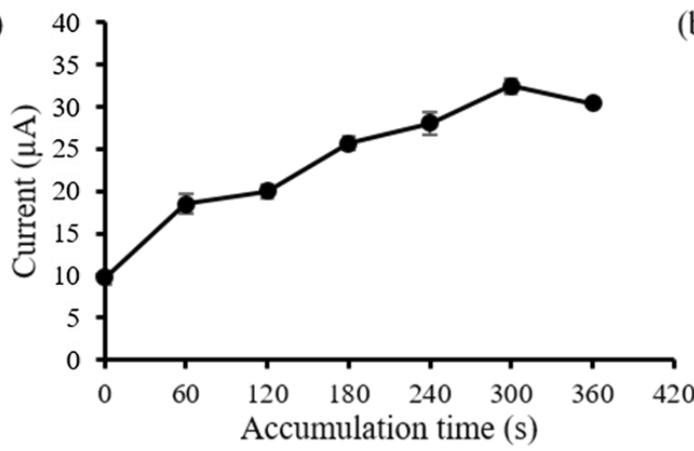

(c)

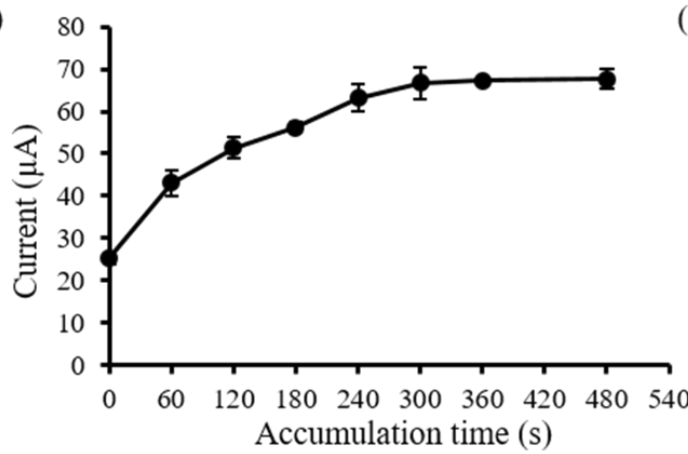

(b)

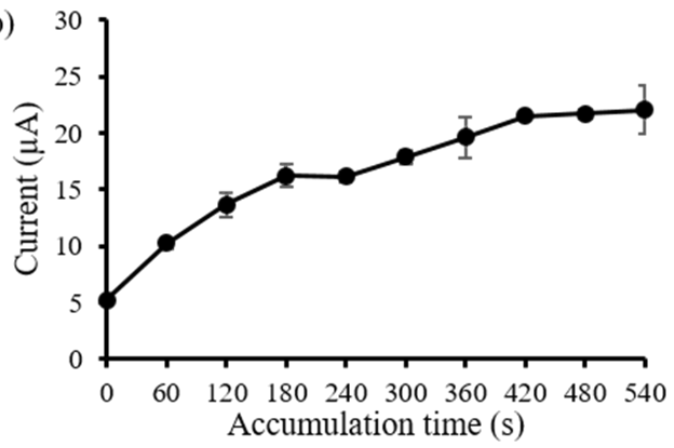

(d)

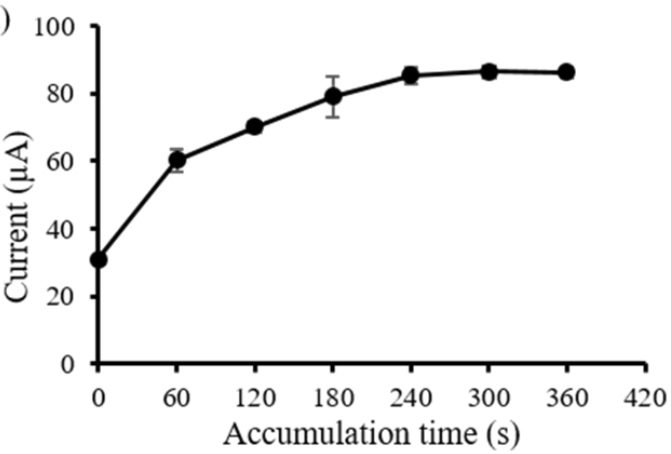

Figure 6. Oxidative current response of $50 \mu \mathrm{M}$ of amaranth (a), tartrazine (b), sunset yellow (c), and carminic acid (d) at different accumulation time. 


\subsection{Determination of Linear Range and Detection Limit}

DPV was utilized to determine the linear detection range of amaranth, tartrazine, sunset yellow, and carminic acid. Step potential at $0.01 \mathrm{~V}$ and modulation amplitude at $0.1 \mathrm{~V}$ were applied for all determinations. Each concentration was tested in triplicate. The two linear detection ranges were observed. For amaranth, the detection was performed under potential from 0.5 to $1 \mathrm{~V}$ in acetate buffer $\mathrm{pH} 4.0$ with accumulation time at $300 \mathrm{~s}$. The current response increased proportionally with concentration of amaranth. Two linear detection ranges were obtained at 1 to 10 and 10 to $100 \mu \mathrm{M}$ of amaranth, as shown in Figure 7a. The equations can be expressed as $y=1.3824 x-0.0266, R^{2}=0.9902$, and $y=0.3202 x+13.283, R^{2}=0.9631$. The limit of detection (LOD) was calculated from 3 times the standard deviation of the blank $(n=10)$ divided by the slope from the linear range, thus the LOD was obtained at $57 \mathrm{nM}$.

(a)

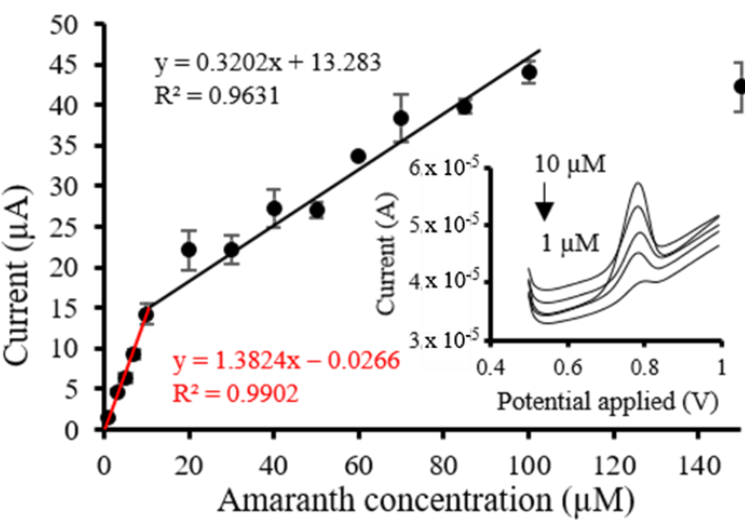

(c)

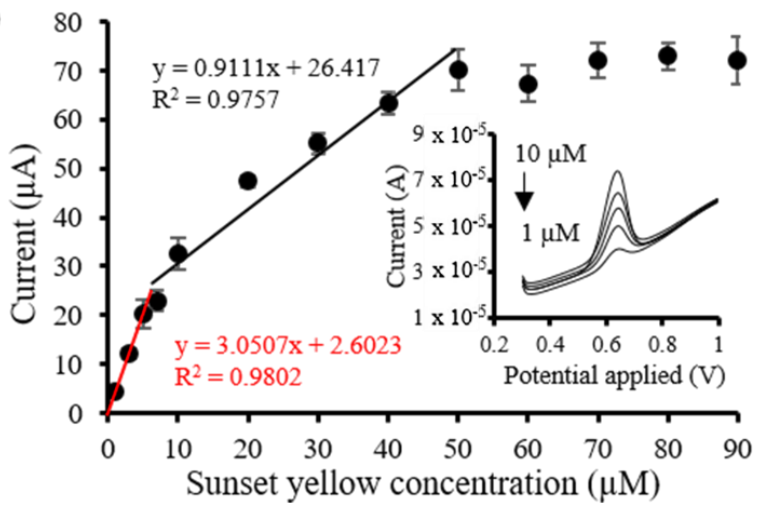

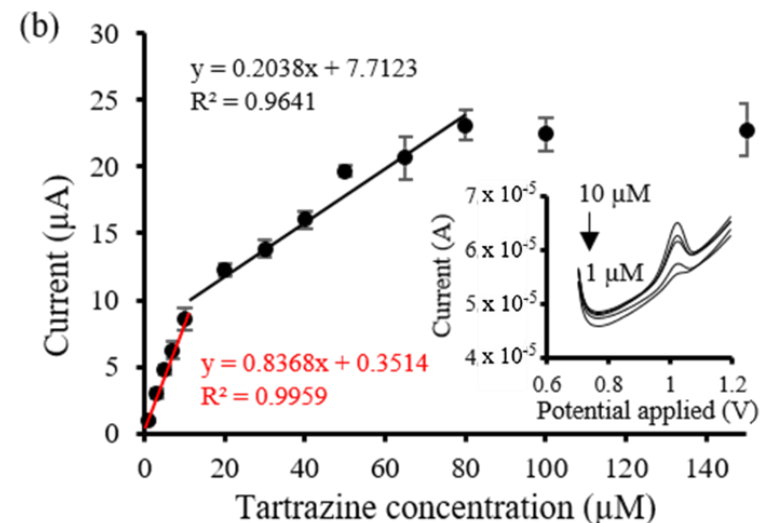

(d)

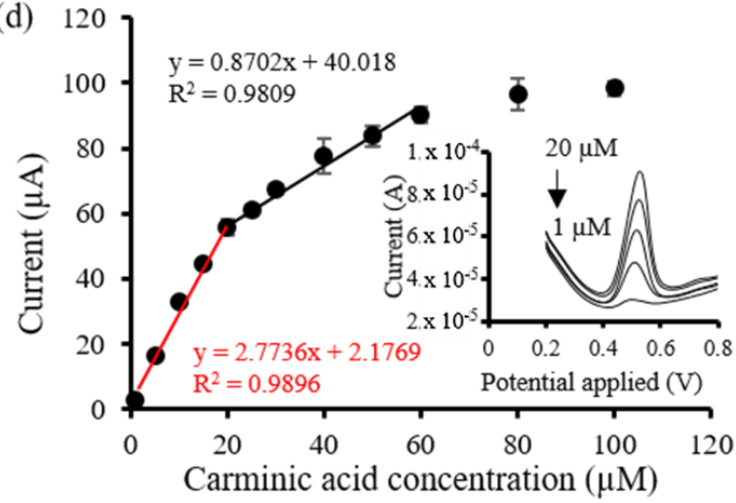

Figure 7. The linear relationship between the oxidative current response and concentration of amaranth (a), tartrazine (b), sunset yellow (c), and carminic acid (d). The insets represent the differential pulse voltammograms at the first linear detection range of each dye.

For tartrazine, potential range of 0.7 to $1.2 \mathrm{~V}$, citrate phosphate buffer $\mathrm{pH} 3.0$, and accumulation time of $420 \mathrm{~s}$ were used for tartrazine determination. Oxidative current also increased proportionally with tartrazine concentration. Figure $7 \mathrm{~b}$ demonstrates linear detection ranges of tartrazine at 1 to 10 and 10 to $85 \mu \mathrm{M}$. The linear equations were obtained as $y=0.8368 x+0.3514, R^{2}=0.9959$, and $y=0.2038 x+7.7123, R^{2}=0.9641$. LOD was calculated to be $41 \mathrm{nM}$.

For sunset yellow, the determination was done under potential range of 0.3 to $1 \mathrm{~V}$ in phosphate buffer $\mathrm{pH} 7.0$ with accumulation time at $300 \mathrm{~s}$. Current response increased proportionally with increase in sunset yellow concentration and exhibited two detection ranges at 1 to 10 and 10 to $50 \mu \mathrm{M}$ as shown in Figure 7c. The linear equations were expressed as $y=3.0507 x+2.6023, R^{2}=0.9802$, and $y=0.9111 x+26.417, R^{2}=0.9757$. LOD of $48 \mathrm{nM}$ was obtained for sunset yellow determination. 
To determine carminic acid concentration, a potential window from 0.2 to $0.8 \mathrm{~V}$ was applied. The electrochemical determination was done under the condition of citrate phosphate buffer $\mathrm{pH} 3.0$ and accumulation time at $240 \mathrm{~s}$. Two linear ranges were observed as well as the other 3 dyes, but the concentration range was different, as shown in Figure $7 \mathrm{~d}$. The first linear range was observed from 1 to $20 \mu \mathrm{M}$, and the second linear range was observed from 20 to $60 \mu \mathrm{M}$ of carminic acid. Linear equations were demonstrated as $y=2.7736 x+2.1769, R^{2}=0.9896$, and $y=0.8702 x+40.018, R^{2}=0.9809$ while LOD was calculated as $36 \mathrm{nM}$.

However, the optimization conditions were performed at $50 \mu \mathrm{M}$ of detecting dyes which locate in the second linear range of all 4 detecting dyes. The change of slope of peak current versus concentration plot might affect the change in reaction mechanism, number of electrons involved, and accumulation time. Thus, the proposed conditions were the optimal condition for only the linear detection range of $50 \mu \mathrm{M}$. Type of reaction mechanism and number of electron transfer were reported for linear detection range of $50 \mu \mathrm{M}$ as well.

The performance comparison of previous reports and the modified sensor is shown in Table 2. The modified electrode showed excellent and recovery range of detection in all dyes. EFSA has regulated the maximum permitted level (MPL) of use of amaranth at $30 \mathrm{mg} / \mathrm{L}$ for fish roe, aperitif wines, and spirit drinks, including products with less than $15 \%$ alcohol by volume [36]. MPL at 50 and $100 \mathrm{mg} / \mathrm{L}$ of non-alcoholic flavored drinks was defined for sunset yellow [37] and tartrazine [5], respectively. For carminic acid, MPL was set ranging from 50 to $500 \mathrm{mg} / \mathrm{kg}$ in 58 food categories [8]. The obtained LOD of amaranth, tartrazine, sunset yellow, and carminic acid were below the MPL which was regulated by EFSA. Thus, the modified sensor was acceptable. In addition, as the modified sensor was fabricated by using SPCE as based electrode and decoration with inexpensive materials and simple method, it gained the advantages of simple preparation, low cost and short analysis time compared with previous reports. Moreover, given that SPCE is a disposable electrode, the modified electrode can be used as a portable device, which is convenient for on-site detection.

Table 2. Comparison of the analytical performance between the developed sensor and previous electrochemical sensors of amaranth, tartrazine, sunset yellow, and carminic acid.

\begin{tabular}{|c|c|c|c|c|c|c|}
\hline Dyes & Modification & Method & Electrode & $\begin{array}{c}\text { Linear Range } \\
(\mu \mathrm{M})\end{array}$ & LOD (nM) & Ref. \\
\hline \multirow[t]{7}{*}{$\mathrm{AM}$} & PSS-GR-Pd/GCE & DPV & GCE & $0.1-9$ & 7 & [27] \\
\hline & $\mathrm{CPE} / \mathrm{RuO}_{2} / \mathrm{NR} / \mathrm{DPIBr}$ & SWV & $\mathrm{CPE}$ & $0.008-550$ & 3 & [38] \\
\hline & PLA-ERGO/GCE & DPV & GCE & $0.75-75$ & 250 & [21] \\
\hline & 1-M-3-BIBR/CuO/SWCNTs/CPE & SWV & CPE & $0.004-750$ & 1 & [39] \\
\hline & GS/GCE & DPV & GCE & $2500-125,000$ & 0.75 & [40] \\
\hline & $\mathrm{Au} / \mathrm{GTA}$ & LSV & $\mathrm{AuE}$ & $0.3-100$ & 100 & [1] \\
\hline & rGO-methionine/SPCE (This work) & DPV & SPCE & $\begin{array}{c}1-10 \\
10-100\end{array}$ & 57 & - \\
\hline \multirow[t]{6}{*}{$\mathrm{TZ}$} & Microspheres-laccase/AuNPs/SPE & DPV & SPCE & $0.2-14$ & 40 & [41] \\
\hline & PGMCPE & $\mathrm{CV}$ & $\mathrm{CPE}$ & $\begin{array}{c}1-27 \\
35-87\end{array}$ & 283 & [22] \\
\hline & $\mathrm{g}-\mathrm{C}_{3} \mathrm{~N}_{4} /$ Graphite electrode & DPV & Graphite & $0.1-10$ & 210 & [42] \\
\hline & PEDOT@TbHCF/GCE & DPV & GCE & $0.1-206$ & 32 & {$[43]$} \\
\hline & H-SWCNT/SPCE & SWAdV & SPCE & $1-8.5$ & 60 & [31] \\
\hline & rGO-methionine/SPCE (This work) & DPV & SPCE & $\begin{array}{c}1-10 \\
10-85\end{array}$ & 41 & - \\
\hline \multirow[t]{7}{*}{ SY } & $\mathrm{MnO}_{2}$ NRs-ERGO/GCE & LSV & GCE & $\begin{array}{c}0.01-2 \\
2-10 \\
10-100\end{array}$ & 2 & [44] \\
\hline & Re@CDACs/SPCE & Amperometry & SPCE & $0.05-390$ & 16 & [45] \\
\hline & $\mathrm{CS} / \mathrm{GCE}$ & SWAdV & GCE & $0.25-3.25$ & 98 & [46] \\
\hline & NC-CPE & SWV & $\mathrm{CPE}$ & $0.001-0.1$ & 0.2 & [47] \\
\hline & Poly(AAm-co-EMA)/Lac/GCE & DPV & GCE & $0.08-10$ & 20 & [48] \\
\hline & AuNPs/PANI-co-PoAN-co-PoT/GO/AuE & SWV & AuE & $5-500$ & 14.2 & [49] \\
\hline & rGO-methionine/SPCE (This work) & DPV & SPCE & $\begin{array}{c}1-10 \\
10-50\end{array}$ & 48 & - \\
\hline
\end{tabular}


Table 2. Cont.

\begin{tabular}{|c|c|c|c|c|c|c|}
\hline Dyes & Modification & Method & Electrode & $\begin{array}{c}\text { Linear Range } \\
(\mu \mathrm{M})\end{array}$ & LOD (nM) & Ref. \\
\hline \multirow[t]{3}{*}{ CA } & Unmodified & DPP & DME & $1-90$ & 160 & [50] \\
\hline & Pd-AuNPs/Poly(Pr)/GE & SWV & Graphite & $0.01-1$ & 5.9 & [34] \\
\hline & rGO-methionine/SPCE (This work) & DPV & SPCE & $\begin{array}{c}1-20 \\
20-60\end{array}$ & 36 & - \\
\hline
\end{tabular}

PSS = Poly(sodium p-styrenesulfonate; GR = Graphene; $\mathrm{Pd}=$ Palladium nanoparticles; $\mathrm{RuO}_{2} / \mathrm{NR}=\mathrm{RuO} 2$ nano-road. $\mathrm{DPIBr}=1,3-$ dipropylimidazolium bromide; PLA = Poly(L-arginine); ERGO = Electrochemical reduction of graphene oxide; 1-M-3-BIBR = 1-methyl3-butylimidazolium bromide; SWCNTs = Single-wall carbon nanotubes; GS = Graphene nanosheets; GTA $=\mathrm{Graphene} / \mathrm{TiO}{ }_{2}-\mathrm{Ag}$ based composites; AuNPs = Gold nanoparticles; PG = Poly(glycine); g- $\mathrm{C}_{3} \mathrm{~N}_{4}=$ Graphitic carbon nitride; PEDOT@TbHCF = Poly $(3,4-$ ethylenedioxythiophene)@Terbium hexacyanoferrate; H-SWCNT = Double-stranded copper(I) helicate-single-walled carbon nanotube; $\mathrm{MnO}_{2} \mathrm{NRs}=\mathrm{MnO}_{2}$ nanorods; Re@CDACs = Rhenium nanoparticles decorated on activated carbon; $\mathrm{CS}=\mathrm{Chitosan}$; NC = Montmorillonite nanoclay; Poly(AAm-co-EMA) = Poly(acrylamide-co-ethyl methacrylate); PANI-co-PoAN-co-PoT = Poly (aniline-co-o-anisidine-co-otoluidine); Pd-AuNPs = Pd-Au bimetallic nanoparticles; Poly(Pr) = Polypyroline; SWV = square wave voltammetry; LSV = linear sweep voltammetry; $\mathrm{SWV}=$ square wave adsorption voltammetry; $\mathrm{DPP}=$ differential pulse polarography.

\subsection{Interference Test}

In general, soft drinks, beverages, or other confectionaries contain several ingredients, thus there is a need to be concerned about the effect of interference on the performance of the sensor. To study the interference of other substances, the amaranth, tartrazine, sunset yellow, and carminic acid at 5 and $50 \mu \mathrm{M}$ were tested with common substances in beverages at various concentrations. Effect of interference was studied by DPV, and the results of interference substances testing with dye concentration at 5 and $50 \mu \mathrm{M}$ are presented in Tables 3 and 4, respectively. Current responses of with and without interference substance were compared and reported in terms of variance. The results demonstrated that 1000fold concentration of glucose and sucrose, 100-fold concentration of $\mathrm{NaCl}$ and $\mathrm{KCl}$, and 10-fold concentration of glycine, ascorbic acid, and citric acid did not significantly affect the determination of all 4 dyes on both concentrations $(5$ and $50 \mu \mathrm{M})$. The percentage error was obtained below $\pm 5 \%$ which indicated good selectivity for amaranth, tartrazine, sunset yellow, and carminic acid.

Table 3. Effect of interference substances on rGO-methionine/SPCE with dye concentration at $5 \mu \mathrm{M}$.

\begin{tabular}{ccccc}
\hline \multirow{2}{*}{ Substance } & \multicolumn{4}{c}{ Variance } \\
\cline { 2 - 5 } & Amaranth & Tartrazine & Sunset Yellow & Carminic Acid \\
\hline Without substance & 100.00 & 100.00 & 100.00 & 100.00 \\
Glucose 1000x & 104.73 & 96.97 & 99.73 & 98.30 \\
Sucrose 1000x & 102.74 & 95.77 & 98.20 & 99.94 \\
NaCl 100x & 97.16 & 97.25 & 100.05 & 96.77 \\
KCl 100x & 99.14 & 95.82 & 99.62 & 96.48 \\
Glycine 10x & 95.30 & 102.53 & 99.93 & 97.43 \\
Ascorbic acid 10x & 98.48 & 101.49 & 101.51 & 95.95 \\
Citric acid 10x & 95.80 & 102.65 & 98.08 & 104.08 \\
\hline
\end{tabular}

Table 4. Effect of interference substances on rGO-methionine/SPCE with dye concentration at $50 \mu \mathrm{M}$.

\begin{tabular}{ccccc}
\hline \multirow{2}{*}{ Substance } & \multicolumn{4}{c}{ Variance } \\
\cline { 2 - 5 } & Amaranth & Tartrazine & Sunset Yellow & Carminic Acid \\
\hline Without substance & 100.00 & 100.00 & 100.00 & 100.00 \\
Glucose 1000x & 104.01 & 97.84 & 103.33 & 97.24 \\
Sucrose 1000x & 99.38 & 100.95 & 103.37 & 96.61 \\
NaCl 100x & 101.41 & 103.76 & 96.94 & 100.61 \\
KCl 100x & 104.21 & 99.62 & 99.33 & 102.94 \\
Glycine 10x & 99.57 & 98.84 & 98.94 & 103.60 \\
Ascorbic acid 10x & 98.36 & 97.24 & 98.98 & 104.08 \\
Citric acid 10x & 95.36 & 104.11 & 97.42 & 102.54 \\
\hline
\end{tabular}




\subsection{Real Sample Analysis}

To study the performance of the modified sensor, it was tested with real samples. The standard addition method was used to determine concentration of amaranth, tartrazine, sunset yellow, and carminic acid in real sample. The rGO-methionine/SPCE was evaluated with 2 groups of sample with and without target dye. Sprite no sugar (lemon-lime flavored soft drink) was tested as a sample without target dyes. Spy wine cooler (red) was tested as a sample containing target amaranth dye. 100 Plus lemon lime flavored carbonated drink and Sponsor active vitamin $\mathrm{C}$ lemon lime flavored were evaluated for tartrazine detection. Two orange flavor soft drinks, Mirinda and Fanta, were tested for sunset yellow determination. Betagen (strawberry flavored probiotic milk beverage) and Nestlé Eskimo Ice-Cream (Nomyen flavored ice cream with milk flavored white compound coating) were tested for carminic acid evaluation. The results presented in Tables 5-8 are for amaranth, tartrazine, sunset yellow, and carminic acid, respectively. The great percentage recovery obtained for all 4 dyes indicated great performance, high accuracy, and reliability of the modified sensor for real sample analysis.

Moreover, UV-Vis spectrophotometer, was tested to confirm the performance of rGOmethionine/SPCE. Unfortunately, the real samples containing the interested dyes show high interference when measured using UV-Vis absorbance measurement. The other substances as well as its translucence interfered the absorbance. Therefore, only 1 sample (Sprite) with the spiked dye solution can be compared by this method. The standard addition method was also used for dyes determination. The result of UV-Vis measurement shows in the parentheses in Tables 5-8. The result showed satisfying \%recovery for all 4 detecting dyes. Moreover, the \%recovery from UV-Vis measurement and the rGOmethionine/SPCE was about the same, indicating that the modified electrode was reliable for amaranth, tartrazine, sunset yellow, and carminic acid determination.

Table 5. Performance of modified sensor for amaranth determination in real sample.

\begin{tabular}{ccccc}
\hline Sample & Added $(\boldsymbol{\mu M})$ & Expected $(\mu \mathbf{M})$ & Found $(\boldsymbol{\mu M})$ & Recovery $(\%)$ \\
\hline \multirow{3}{*}{ Sprite } & 0.00 & & Not found & \\
& 1.50 & 1.50 & $1.49(1.41)$ & $99.45(94.02)$ \\
& 2.00 & 2.00 & $2.01(1.90)$ & $100.44(95.01)$ \\
& 2.50 & 2.50 & $2.51(2.41)$ & $100.36(96.30)$ \\
\hline \multirow{3}{*}{ SPY classic red } & 0.00 & & 0.52 & \\
& 1.50 & 2.02 & 1.95 & 96.44 \\
& 2.00 & 2.52 & 2.45 & 97.29 \\
& 2.50 & 3.02 & 3.10 & 102.87 \\
\hline
\end{tabular}

Table 6. Performance of modified sensor for tartrazine determination in real sample.

\begin{tabular}{ccccc}
\hline Sample & Added $(\mu \mathbf{M})$ & Expected $(\mu \mathbf{M})$ & Found $(\mu \mathbf{M})$ & Recovery $(\%)$ \\
\hline \multirow{3}{*}{ Sprite } & 0.00 & & Not found & \\
& 1.50 & 1.50 & $1.55(1.48)$ & $103.43(98.34)$ \\
& 2.00 & 2.00 & $2.01(2.05)$ & $100.48(102.36)$ \\
& 2.50 & 2.50 & $2.49(2.40)$ & $99.53(96.12)$ \\
\hline \multirow{2}{*}{ 100 Plus } & 0.00 & & 0.98 & \\
& 3.00 & 3.98 & 4.15 & 104.21 \\
& 4.00 & 4.98 & 4.91 & 98.46 \\
Sponsor lemon & 5.00 & 5.98 & 6.27 & 104.85 \\
lime & 0.00 & & 1.82 & \\
& 4.00 & 5.82 & 5.58 & 95.90 \\
& 5.00 & 6.82 & 6.42 & 94.14 \\
& 6.00 & 7.82 & 7.89 & 100.82 \\
\hline
\end{tabular}


Table 7. Performance of modified sensor for sunset yellow determination in real sample.

\begin{tabular}{ccccc}
\hline Scheme & Added $(\mu \mathbf{M})$ & Expected $(\mu \mathbf{M})$ & Found $(\mu \mathbf{M})$ & Recovery $(\%)$ \\
\hline \multirow{2}{*}{ Sprite } & 0.00 & & Not found & \\
& 1.50 & 1.50 & $1.29(1.57)$ & $85.98(104.76)$ \\
& 2.00 & 2.00 & $1.92(1.99)$ & $96.12(99.70)$ \\
& 2.50 & 2.50 & $2.40(2.48)$ & $95.99(99.17)$ \\
\hline \multirow{3}{*}{ Mirinda (orange) } & 0.00 & & 1.10 & \\
4 fold dilution & 3.00 & 4.10 & 4.24 & 103.38 \\
& 4.00 & 5.10 & 5.18 & 101.50 \\
& 5.00 & 6.10 & 6.20 & 101.63 \\
Fanta (orange) & 0.00 & & 2.71 & \\
& 3.00 & 5.71 & 5.71 & 100.01 \\
& 5.00 & 7.71 & 7.26 & 94.06 \\
\hline
\end{tabular}

Table 8. Performance of modified sensor for carminic acid determination in real sample.

\begin{tabular}{ccccc}
\hline Sample & Added $(\boldsymbol{\mu M})$ & Expected $(\mu \mathbf{M})$ & Found $(\mu \mathbf{M})$ & Recovery $(\%)$ \\
\hline & 0.00 & 0.00 & & \\
Sprite & 5.00 & 5.00 & $5.48(4.87)$ & $109.63(97.40)$ \\
& 10.00 & 10.00 & $11.13(9.72)$ & $111.29(97.24)$ \\
& 15.00 & 15.00 & $15.58(14.28)$ & $103.87(95.23)$ \\
\hline Betagan & 0.00 & & 0.46 & \\
strawberry & 3.00 & 3.46 & 3.14 & 90.75 \\
flavour & 4.00 & 4.46 & 4.14 & 92.95 \\
& 5.00 & 5.46 & 4.85 & 88.93 \\
Ice-cream Nestle & 0.00 & & 0.95 & \\
Eskimo & 3.00 & 3.95 & 3.31 & 83.83 \\
(2 fold dilution) & 4.00 & 4.95 & 4.36 & 88.12 \\
& 5.00 & 5.95 & 4.86 & 81.66 \\
\hline
\end{tabular}

\subsection{Reproducibility Test}

To study reproducibility of modified sensor, the rGO-methionine/SPCE was tested with $50 \mu \mathrm{M}$ of amaranth, tartrazine, sunset yellow, and carminic acid on 50 independent modified electrodes. The repeatability performance was reported in terms of the percent of relative standard deviation (\%RSD). The \%RSD was found to be $8.98,6.49,8.91$, and 4.17 for amaranth, tartrazine, sunset yellow, and carmnic acid, respectively. The \%RSD of ama-ranth, tartrazine, and sunset yellow was over $5 \%$, but below $10 \%$, indicating the slight ef-fect of independent preparation.

\section{Materials and Methods}

\subsection{Reagents and Apparatus}

Graphene oxide (GO), L-methionine, amaranth, sunset yellow, and tartrazine were purchased from Sigma-Aldrich Pte. Ltd. (Singapore). Carminic acid was obtained from Tokyo Chemical Industry (TCI) (Tokyo, Japan). All other chemicals were of analytical grade. All supporting electrolytes were prepared with milliQ water. Citrate-Phosphate buffer $\mathrm{pH}$ 2.5 and 3.0 were prepared from adjusting solution between $0.1 \mathrm{M}$ citric acid and $0.2 \mathrm{M}$ $\mathrm{Na}_{2} \mathrm{HPO}_{4}$. Acetate buffer $\mathrm{pH} 4.0$ and 5.0 were prepared from mixing solution of $0.1 \mathrm{M}$ acetic acid and $0.1 \mathrm{M}$ of sodium acetate. Phosphate buffer solution (PBS) $\mathrm{pH}$ 6.0-8.0 were prepared from $0.1 \mathrm{M} \mathrm{Na}_{2} \mathrm{HPO}_{4}$ and $0.1 \mathrm{M} \mathrm{NaH}_{2} \mathrm{PO}_{4}$. All electrolytes were prepared using $0.1 \mathrm{M} \mathrm{KCl}$ and purged with nitrogen gas for at least $30 \mathrm{~min}$ to eliminate dissolved oxygen.

All the electrochemical measurements including CV, EIS, and DPV were performed on Autolab PGSTAT128N with NOVA software version 1.11. Screen printed carbon electrode (SPCE) was purchased from Quasence. Co, Ltd. (Bangkok, Thailand). The working elec- 
trode's area was $3 \mathrm{~mm}^{2}$. A conventional three-electrode system containing the modified SPCE was used as working electrode, $\mathrm{Ag} / \mathrm{AgCl}$ as reference electrode and platinum wire as counter electrode. UV-Vis spectrophotometer was used as a standard method for compar-ing in real sample analysis. The detecting samples for amaranth, tartrazine, sunset yel-low, and carminic acid were measured at the wavelength of 520, 426, 485, and $500 \mathrm{~nm}$, respectively.

\subsection{Synthesis of $r G O$}

Reduced graphene oxide was prepared by glucose reduction [51,52]. Firstly, $10 \mathrm{mg}$ of graphene oxide (GO) and $40 \mathrm{mg}$ of glucose were dispersed in $10 \mathrm{~mL}$ of deionized (DI) water. The mixed solution was stirred for $30 \mathrm{~min}$ at $95^{\circ} \mathrm{C}$. Thereafter, $100 \mu \mathrm{L}$ of ammonium hy-droxide $\left(\sim 25 \% \mathrm{NH}_{3}\right.$ basis $)$ was added by dropping. Then, the mixed solution was stirred for $1 \mathrm{~h}$ at $95^{\circ} \mathrm{C}$. The rGO was collected by filtration on nitrocellulose membrane with $0.45 \mu \mathrm{m}$ pore size and washed with DI water until filtrated solution attained a $\mathrm{pH}$ of 7.0. The synthesized rGO was separated from membrane by sonication in DI water. Thereafter, the dispersed rGO was collected by centrifugation. The precipitated rGO was dried overnight at $37^{\circ} \mathrm{C}$ and kept in dry condition.

\subsection{Preparation of rGO-Methionine Modified SPCE}

The synthesized rGO was modified on SPCE by drop-casting. Firstly, $1 \mathrm{mg}$ of prepared rGO was dispersed in $1 \mathrm{~mL}$ of $30 \%$ ethanol and sonicated for $30 \mathrm{~min}$. Then, $3 \mu \mathrm{L}$ of well-dispersed rGO was dropped directly on the surface of SPCE. The rGO modified SPCE was dried in a desiccator for $2 \mathrm{~h}$. Poly(L-methionine) film was modified on rGO modified SPCE by electrochemical polymerization. CV was carried out in PBS pH 7.0 containing $2.5 \mathrm{mM}$ of L-methionine with potential range of -0.6 to $2.0 \mathrm{~V}$ at scan rate of $100 \mathrm{mV} / \mathrm{s}$ for 3 cy-cles. After polymerization, the rGO-methionine modified SPCE was rinsed with DI water and dried overnight in the desiccator. Schematic representation of modification process is illustrated in Scheme 2.

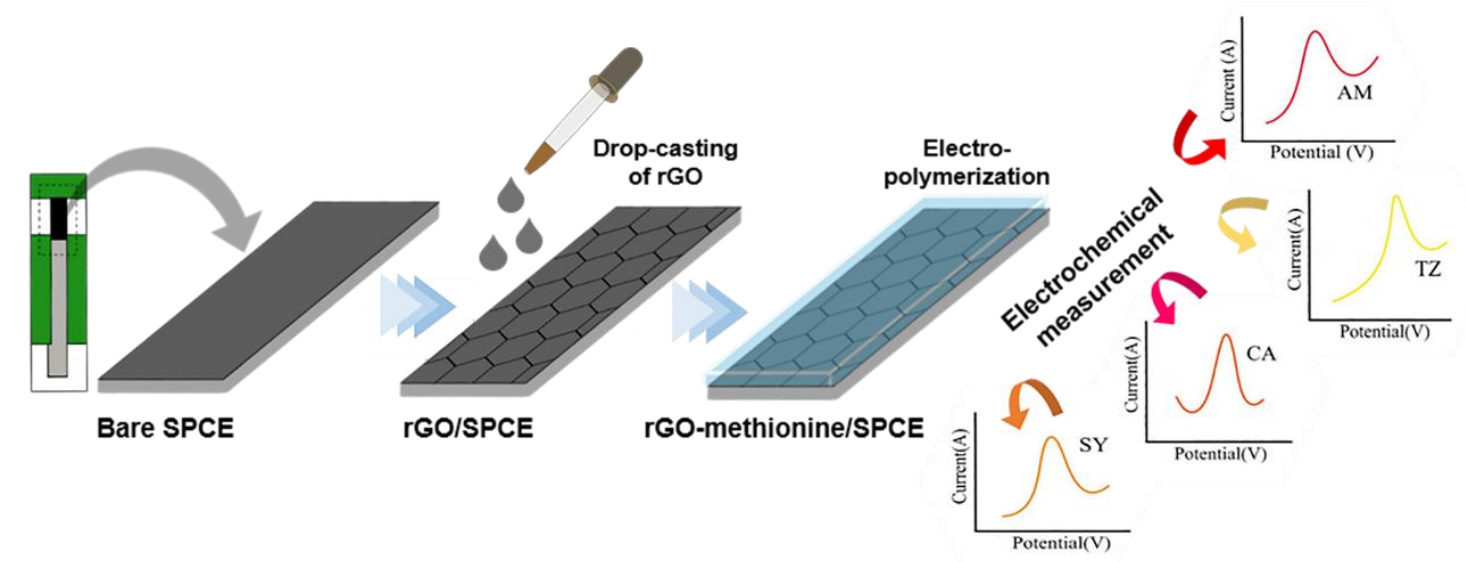

Scheme 2. Schematic representation of modification process of rGO-methionine/SPCE.

\section{Conclusions}

In conclusion, we reported the electrochemical determination of amaranth, tartrazine, sunset yellow, and carminic acid by SPCE modified with rGO and methionine film. With the synergistic effect of rGO and methionine film, the modified sensor significantly enhanced the catalytic activity, exhibited wide linear range, and demonstrated low detection limit of these 4 dyes. Moreover, the modified sensor showed great performance in selectivity and repeatability as well as in real sample analysis. Thus, the proposed sensor can be a good alternative for food dyes determination. 
Author Contributions: Conceptualization, R.P.P.-a.; methodology, R.P.P.-a., C.A., K.S. and Y.P.-a.; validation, C.A., K.S. and Y.P.-a.; investigation, R.P.P.-a., C.A. and Y.P.-a.; writing-original draft preparation, C.A.; writing-review and editing, R.P.P.-a.; visualization, C.A. All authors have read and agreed to the published version of the manuscript.

Funding: This research was funded by the Thailand Science Research and Innovation (TSRI) [grant number RSA6280008] and the Research Strengthening Project of the Faculty of Engineering, King Mongkut's University of Technology Thonburi. King Mongkut's University of Technology Thonburi: KMUTT Partnering Initiative grant fiscal year 2021 under KIRIM number 4811.

Institutional Review Board Statement: Not applicable.

Informed Consent Statement: Not applicable.

Data Availability Statement: The data presented in this sudy are available on request from the corresponding author.

Acknowledgments: C.A. would like to thanks to Petchra Pra Jom Klao Ph.D. Research Scholarship from King Mongkut's University of Technology Thonburi.

Conflicts of Interest: The authors declare no conflict of interest.

Sample Availability: Not available.

\section{References}

1. Pogacean, F.; Rosu, M.C.; Coros, M.; Magerusan, L.; Moldovan, M.; Sarosi, C.; Porav, A.-S.; Stefan-van Staden, R.-I.; Pruneanu, S. Graphene $/ \mathrm{TiO}_{2}-\mathrm{Ag}$ Based Composites Used as Sensitive Electrode Materials for Amaranth Electrochemical Detection and Degradation. J. Electrochem. Soc. 2018, 165, B3054-B3059. [CrossRef]

2. Stevens, L.J.; Kuczek, T.; Burgess, J.R.; Stochelski, M.A.; Arnold, L.E.; Galland, L. Mechanisms of behavioral, atopic, and other reactions to artificial food colors in children. Nutr. Rev. 2013, 71, 268-281. [CrossRef]

3. European Food Safety Authorit. Refined exposure assessment for amaranth (E 123). EFSA J. 2013, 11, 3442.

4. EFSA ANS Panel (Panel on Food Additives and Nutrient Sources Added to Food). Scientific opinion on the reconsideration of the temporary ADI and refined exposure assessment for Sunset Yellow FCF (E 110). EFSA J. 2014, 12, 3765. [CrossRef]

5. EFSA Panel on Food Additives and Nutrient Sources Added to Food (ANS). Scientific Opinion on the re-evaluation Tartrazine (E 102). EFSA J. 2009, 7, 1331. [CrossRef]

6. Lipskikh, O.I.; Korotkova, E.I.; Khristunova, Y.P.; Barek, J.; Kratochvil, B. Sensors for voltammetric determination of food azo dyes-A critical review. Electrochim. Acta 2018, 260, 974-985. [CrossRef]

7. Borges, M.E.; Tejera, R.L.; Díaz, L.; Esparza, P.; Ibáñez, E. Natural dyes extraction from cochineal (Dactylopius coccus). New extraction methods. Food Chem. 2012, 132, 1855-1860. [CrossRef]

8. EFSA Panel on Food Additives and Nutrient Sources Added to Food. Scientific Opinion on the re-evaluation of cochineal, carminic acid, carmines (E 120) as a food additive. EFSA J. 2015, 13, 4288. [CrossRef]

9. Müller-Maatsch, J.; Gras, C. 18-The "Carmine Problem" and Potential Alternatives11Both Authors Contributed Equally to this Chapter, in Handbook on Natural Pigments in Food and Beverages; Carle, R., Schweiggert, R.M., Eds.; Woodhead Publishing: Cambridge, UK, 2016; pp. 385-428.

10. Hashem, E.; Saleh, M.S.; Al-Salahi, N.O.; Youssef, A.K. Advanced Spectrophotometric Analysis of Sunset Yellow Dye E110 in Commercial Food Samples. Food Anal. Methods 2017, 10, 865-875. [CrossRef]

11. Heidarizadi, E.; Tabaraki, R. Simultaneous spectrophotometric determination of synthetic dyes in food samples after cloud point extraction using multiple response optimizations. Talanta 2016, 148, 237-246. [CrossRef]

12. Rovina, K.; Siddiquee, S.; Shaarani, S.M. Extraction, Analytical and Advanced Methods for Detection of Allura Red AC (E129) in Food and Beverages Products. Front. Microbiol. 2016, 7, 798. [CrossRef] [PubMed]

13. Liu, F.-J.; Liu, C.-T.; Li, W.; Tang, A.-N. Dispersive solid-phase microextraction and capillary electrophoresis separation of food colorants in beverages using diamino moiety functionalized silica nanoparticles as both extractant and pseudostationary phase. Talanta 2015, 132, 366-372. [CrossRef]

14. Ashwin Karthick, N.; Thangappan, R.; Arivanandhan, M.; Gnanamani, A.; Jayavel, R. A Facile Synthesis of Ferrocene Functionalized Graphene Oxide Nanocomposite for Electrochemical Sensing of Lead. J. Inorg. Organomet. Polym. Mater. 2018, 28, $1021-1028$. [CrossRef]

15. Zhang, B.; Zhang, J.; Lin, Y.; Liu, M.; Fang, G.; Wang, S. Coral-like Au1Pt3 alloy nanoparticles with multiple surface defects modified by poly(L-methionine) membrane for the selective detection of dopamine in biological samples. J. Alloy. Compd. 2020, 815, 152643. [CrossRef]

16. Thomas, D.; Rasheed, Z.; Jagan, J.S.; Kumar, K.G. Study of kinetic parameters and development of a voltammetric sensor for the determination of butylated hydroxyanisole (BHA) in oil samples. J. Food Sci. Technol. 2015, 52, 6719-6726. [CrossRef] 
17. Ojani, R.; Alinezhad, A.; Abedi, Z. A highly sensitive electrochemical sensor for simultaneous detection of uric acid, xanthine and hypoxanthine based on poly(l-methionine) modified glassy carbon electrode. Sens. Actuators B Chem. 2013, 188, 621-630. [CrossRef]

18. Wang, S.-F.; Du, D.; Zou, Q.-C. Electrochemical behavior of epinephrine at l-cysteine self-assembled monolayers modified gold electrode. Talanta 2002, 57, 687-692. [CrossRef]

19. He, J.; Zhongrong, S.O.N.G.; Zhang, S.; Lin, W.A.N.G.; Zhang, Y.; Ri, Q.I.U. Methionine-Au Nanoparticle Modified Glassy Carbon Electrode: A Novel Platform for Electrochemical Detection of Hydroquinone. Medziagotyra 2014, 20, 381-386. [CrossRef]

20. Zhang, F.; Wang, Z.; Zhang, Y.; Zheng, Z.; Wang, C.; Du, Y.; Ye, W. Simultaneous electrochemical determination of uric acid, xanthine and hypoxanthine based on poly(l-arginine)/graphene composite film modified electrode. Talanta 2012, 93, 320-325. [CrossRef]

21. Hu, Q.Q.; Gao, H.; Wang, Y.M.; Ma, W.; Sun, D.M. Simultaneous Determination of Carmine and Amaranth Based on a Poly(LArginine)-Graphene Modified Electrode. J. Anal. Chem. 2018, 73, 817-823. [CrossRef]

22. Manjunatha, J.G. A novel voltammetric method for the enhanced detection of the food additive tartrazine using an electrochemical sensor. Heliyon 2018, 4, e00986. [CrossRef]

23. Chao, M.; Ma, X. Convenient Electrochemical Determination of Sunset Yellow and Tartrazine in Food Samples Using a Poly(LPhenylalanine)-Modified Glassy Carbon Electrode. Food Anal. Methods 2015, 8, 130-138. [CrossRef]

24. Tang, Y.; Wang, Y.; Liu, G.; Sun, D. Determination of sunset yellow and tartrazine using silver and poly (L-cysteine) composite film modified glassy carbon electrode. Indian J. Chem. Sect. A 2016, 55, 298-303.

25. Zhang, K.; Luo, P.; Wu, J.; Wang, W.; Ye, B. Highly sensitive determination of Sunset Yellow in drink using a poly (L-cysteine) modified glassy carbon electrode. Anal. Methods 2013, 5, 5044. [CrossRef]

26. Gördük, Ö.; Şahin, Y. Poly(L-Cysteine) Modified Pencil Graphite Electrode for Determination of Sunset Yellow in Food and Beverage Samples by Differential Pulse Voltammetry. Int. J. Electrochem. Sci. 2018, 13, 159-174.

27. Gao, Y.; Wang, L.; Zhang, Y.; Zou, L.; Li, G.; Ye, B. Electrochemical behavior of amaranth and its sensitive determination based on Pd-doped polyelectrolyte functionalized graphene modified electrode. Talanta 2017, 168, 146-151. [CrossRef]

28. Jing, S.; Zhang, H.; Zhao, L.; Qu, L.; Yu, L. Electrochemical Sensor Based on Poly(Sodium 4-Styrenesulfonate) Functionalized Graphene and $\mathrm{Co}_{3} \mathrm{O}_{4}$ Nanoparticle Clusters for Detection of Amaranth in Soft drinks. Food Anal. Methods 2017, 10, 3149-3157. [CrossRef]

29. Wang, M.; Cui, M.; Zhao, M.; Cao, H. Sensitive determination of Amaranth in foods using graphene nanomeshes. J. Electroanal. Chem. 2018, 809, 117-124. [CrossRef]

30. Arvand, M.; Gaskarmahalleh, A.A.; Hemmati, S. Enhanced-Oxidation and Highly Sensitive Detection of Tartrazine in Foodstuffs via New Platform Based on Poly(5-Sulfosalicylic Acid)/Cu(OH $)_{2}$ Nanoparticles. Food Anal. Methods 2017, 10, 2241-2251. [CrossRef]

31. Nuñez-Dallos, N.; Macías, M.A.; García-Beltrán, O.; Calderón, J.A.; Nagles, E.; Hurtado, J. Voltammetric determination of amaranth and tartrazine with a new double-stranded copper (I) helicate-single-walled carbon nanotube modified screen printed electrode. J. Electroanal. Chem. 2018, 822, 95-104. [CrossRef]

32. Arvand, M.; Erfanifar, Z.; Ardaki, M.S. A New Core@Shell Sili00CA-Coated Magnetic Molecular Imprinted Nanoparticles for Selective Detection of Sunset Yellow in Food Samples. Food Anal. Methods 2017, 10, 2593-2606. [CrossRef]

33. Chebotarev, A.; Koicheva, A.; Bevziuk, K.; Pliuta, K.; Snigur, D. Simultaneous determination of Sunset Yellow and Tartrazine in soft drinks on carbon-paste electrode modified by silica impregnated with cetylpyridinium chloride. J. Food Meas. Charact. 2019, 13, 1964-1972. [CrossRef]

34. Arslan, E.; Çakır, S. Electrochemical fabrication of polyproline modified graphite electrode decorated with Pd-Au bimetallic nanoparticles: Application for determination of carminic acid. J. Electroanal. Chem. 2016, 760, 32-41. [CrossRef]

35. Wang, M.; Sun, Y.; Yang, X.; Zhao, J. Sensitive determination of Amaranth in drinks by highly dispersed CNT in graphene oxide "water" with the aid of small amounts of ionic liquid. Food Chem. 2015, 179, 318-324. [CrossRef] [PubMed]

36. EFSA Panel on Food Additives and Nutrient Sources Added to Food (ANS). Scientific Opinion on the re-evaluation of Amaranth (E 123) as a food additive. EFSA J. 2010, 8, 1649. [CrossRef]

37. EFSA Panel on Food Additives and Nutrient Sources Added to Food (ANS). Scientific Opinion on the re-evaluation of Sunset Yellow FCF (E 110) as a food additive. EFSA J. 2009, 7, 1330. [CrossRef]

38. Sheikhshoaie, M.; Karimi-Maleh, H.; Sheikhshoaie, I.; Ranjbar, M. Voltammetric amplified sensor employing $\mathrm{RuO}_{2}$ nano-road and room temperature ionic liquid for amaranth analysis in food samples. J. Mol. Liq. 2017, 229, 489-494. [CrossRef]

39. Bijad, M.; Karimi-Maleh, H.; Farsi, M.; Shahidi, S.A. Simultaneous Determination of Amaranth and Nitrite in Foodstuffs via Electrochemical Sensor Based on Carbon Paste Electrode Modified with CuO/SWCNTs and Room Temperature Ionic Liquid. Food Anal. Methods 2017, 10, 3773-3780. [CrossRef]

40. Huang, W.; Zhang, M.; Hu, W. N-methyl-2-pyrrolidone-exfoliated graphene nanosheets as sensitive determination platform for amaranth at the nanomolar level. Ionics 2017, 23, 241-246. [CrossRef]

41. Mazlan, S.Z.; Lee, Y.H.; Hanifah, S.A. A New Laccase Based Biosensor for Tartrazine. Sensors 2017, 17, 2859. [CrossRef]

42. Karimi, M.A.; Aghaei, V.H.; Nezhadali, A.; Ajami, N. Graphitic Carbon Nitride as a New Sensitive Material for Electrochemical Determination of Trace Amounts of Tartrazine in Food Samples. Food Anal. Methods 2018, 11, 2907-2915. [CrossRef]

43. Sakthivel, M.; Sivakumar, M.; Chen, S.M.; Pandi, K. Electrochemical synthesis of poly(3,4-ethylenedioxythiophene) on terbium hexacyanoferrate for sensitive determination of tartrazine. Sens. Actuators B Chem. 2018, 256, 195-203. [CrossRef] 
44. Ding, Z.; Deng, P.; Wu, Y.; Tian, Y.; Li, G.; Liu, J.; He, Q. A Novel Modified Electrode for Detection of the Food Colorant Sunset Yellow Based on Nanohybrid of MnO2 Nanorods-Decorated Electrochemically Reduced Graphene Oxide. Molecules 2019, 24, 1178. [CrossRef] [PubMed]

45. Kumar, D.P.V.; Rajkumar, C.; Chen, S.M.; Thirumalraj, B.; Lin, K.C. Activated porous carbon supported rhenium composites as electrode materials for electrocatalytic and supercapacitor applications. Electrochim. Acta 2018, 271, $433-447$.

46. Peña-Gonzalez, A. Detection of Sunset Yellow by Adsorption Voltammetry at Glassy Carbon Electrode Modified with Chitosan. Int. J. Electrochem. Sci. 2018, 13, 5005-5015. [CrossRef]

47. Shetti, N.; Nayak, D.; Malode, S. Electrochemical behavior of azo food dye at nanoclay modified carbon electrode-a nanomolar determination. Vacuum 2018, 155, 524-530. [CrossRef]

48. Rozi, N.; Ahmad, A.; Yook Heng, L.; Shyuan, L.K.; Hanifah, S.A. Electrochemical Sunset Yellow Biosensor Based on Photocured Polyacrylamide Membrane for Food Dye Monitoring. Sensors 2018, 18, 101. [CrossRef]

49. Wang, J.; Yang, B.; Zhang, K.; Bin, D.; Shiraishi, Y.; Yang, P.; Du, Y. Highly sensitive electrochemical determination of Sunset Yellow based on the ultrafine Au-Pd and reduced graphene oxide nanocomposites. J. Colloid Interface Sci. 2016, 481, 229-235. [CrossRef]

50. Yilmaz, U.T.; Ergun, F.; Yilmaz, H. Determination of the food dye carmine in milk and candy products by differential pulse polarography. J. Food Drug Anal. 2014, 22, 329-335. [CrossRef]

51. Pakapongpan, S.; Tuantranont, A.; Poo-arporn, R.P. Magnetic Nanoparticle-Reduced Graphene Oxide Nanocomposite as a Novel Bioelectrode for Mediatorless-Membraneless Glucose Enzymatic Biofuel Cells. Sci. Rep. 2017, 7, 12882. [CrossRef]

52. Poo-arporn, Y.; Pakapongpan, S.; Chanlek, N.; Poo-arporn, R.P. The development of disposable electrochemical sensor based on $\mathrm{Fe} 3 \mathrm{O} 4$-doped reduced graphene oxide modified magnetic screen-printed electrode for ractopamine determination in pork sample. Sens. Actuators B Chem. 2019, 284, 164-171. [CrossRef] 